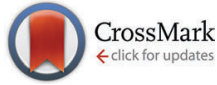

Cite this: Chem. Commun., 2014, 50, 12476

Received 17th July 2014, Accepted 27th August 2014

DOI: $10.1039 / c 4 c c 05525$

www.rsc.org/chemcomm

\section{Coordination-Induced Spin-State-Switch (CISSS) in water $\dagger$}

\author{
Marcel Dommaschk, ${ }^{a}$ Florian Gutzeit, ${ }^{a}$ Susann Boretius, ${ }^{b}$ Rainer $\mathrm{Haag}^{\mathrm{c}}$ and \\ Rainer Herges*a
}

\begin{abstract}
We present a non-ionic water-soluble porphyrin that does not exhibit measurable aggregation even at high concentrations in water. The spin state of the corresponding nickel(II) complex changes from completely diamagnetic (low-spin) to paramagnetic (high-spin) upon addition of a strong axial ligand. This leads to a strongly reduced NMR relaxation time of the water protons even at low concentrations of the complex.
\end{abstract}

Ni-porphyrins are of strong interest for spin switching in solution. ${ }^{1-6}$ Square planar complexes are diamagnetic (low-spin, $S=0$ ) while square pyramidal and square bipyramidal (distorted octahedral) complexes are paramagnetic (high-spin, $S=1$ ). The transition between the two spin states was coined Coordination Induced Spin-State-Switch (CISSS). Until now this process was limited to organic solutions because porphyrins with the required electronic properties are not soluble in water. We present here the first dendronized porphyrin which undergoes a CISSS in water.

Most of the known water-soluble porphyrins bear solubilizing groups in the meso position. They are either anionic $\mathrm{Ph}_{-} \mathrm{SO}_{3}{ }^{-}$ (TPPS), ${ }^{7,8} \mathrm{Ph}^{-\mathrm{COO}^{-}}$(TPPC), ${ }^{9-12}$ or cationic $\mathrm{Ph}-\mathrm{NMe}_{3}{ }^{+}$(TAPP), ${ }^{13,14}$ $\mathrm{Py}_{-\mathrm{Me}^{+}} \quad(o-, \quad m-, \quad p \text {-TMPyP })^{8,15,16}$ or tetrafluoro-Ph-NMe ${ }_{3}^{+}$ $\left(\mathbf{T A P P F}_{16}\right)^{17,18}$ or they are equipped with neutral hydrophilic groups. None of the corresponding ionic Ni-porphyrins provides the required electronic environment for a CISSS (Fig. 1). Ni(II) complexes of TPPS, TPPC, and TAPP do not coordinate even strong axial ligands in water because they are too electron rich, whereas $o-, m-, p$-TMPyP and $\mathbf{T A P P F}_{\mathbf{1 6}}$ are so electron deficient that even water is coordinating. ${ }^{17-20}$ So far there is no known Ni-porphyrin that is completely diamagnetic in water (no coordination of water as the axial ligand) but which is still

\footnotetext{
${ }^{a}$ Otto-Diels-Institute of Organic Chemistry, Christian-Albrechts-Universität zu Kiel, Otto-Hahn-Platz 4, 24118 Kiel, Germany. E-mail: rherges@oc.uni-kiel.de

${ }^{b}$ Department of Diagnostic Radiology, Christian-Albrechts-Universität zu Kiel, Arnold-Heller-Str. 3, 24105 Kiel, Germany

${ }^{c}$ Institute of Chemistry and Biochemistry, Freie Universität Berlin, Takustr. 3, 14195 Berlin, Germany

$\dagger$ Electronic supplementary information (ESI) available. See DOI: 10.1039/ c4cc05525j
}

a)
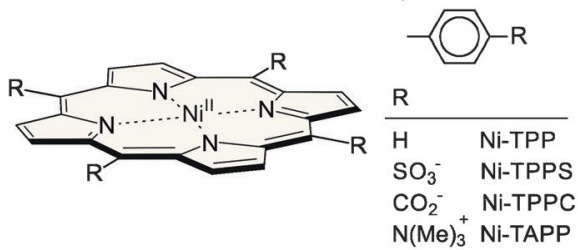

b)

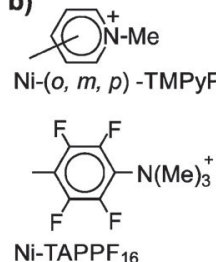

Fig. $1 \mathrm{Ni}$-tetraphenylporphyrin TPP and some water-soluble derivatives. (a) Electron rich porphyrins which do not bind axial ligands in water (diamagnetic). (b) Electron deficient porphyrins which bind water (partially paramagnetic in water).

sufficiently reactive for binding stronger ligands such as piperidine or 1-methylimidazole.

Non-ionic water-soluble porphyrins are gaining interest because they possess advantages in photooxygenation and photodynamic therapy (PDT). ${ }^{21,22}$ Water solubility was achieved by substitution with ethylene glycols, ${ }^{23,24}$ carbohydrates, ${ }^{25-28}$ and polyhydroxyamides. ${ }^{29}$ Griesbeck et al. synthesized water-soluble TPP derivatives decorated with polyols. ${ }^{30}$ Our approach is based on a different kind of polyols namely the dendritic glycerol. It has been shown that these groups are suitable for water solubilisation of organic compounds. ${ }^{31-33}$ In addition it has been demonstrated that oligoglycerol dendrons can provide sufficient shielding to prevent aggregation of planar perylene dye molecules and enhance their quantum yields to almost $100 \%$. $^{34,35}$

We report here on the functionalisation of the established porphyrins $\operatorname{TPPF}_{20}(\mathbf{1})^{36}$ and Ni-TPPF $20(2)^{5}$ with the second generation glycerol $(\mathrm{G}[2.0]-\mathrm{OH})$, and we present the properties of the corresponding water-soluble porphyrins. $\mathrm{TPPF}_{20}$ (1) instead of TPP was chosen as the starting material because it is substantially more electron deficient, which is necessary to achieve axial coordination. Moreover, it is known that amines, alcoholates and thiolates can be introduced into the para-phenyl position by nucleophilic aromatic substitution which is a simple and efficient way of functionalisation. ${ }^{17,18,25,27,28}$ The second generation glycerol $(\mathrm{G}[2.0]-\mathrm{OH})$ was synthesised according to a procedure of Haag et al. as described previously. ${ }^{32}$ The reaction scheme of the functionalisation procedure 

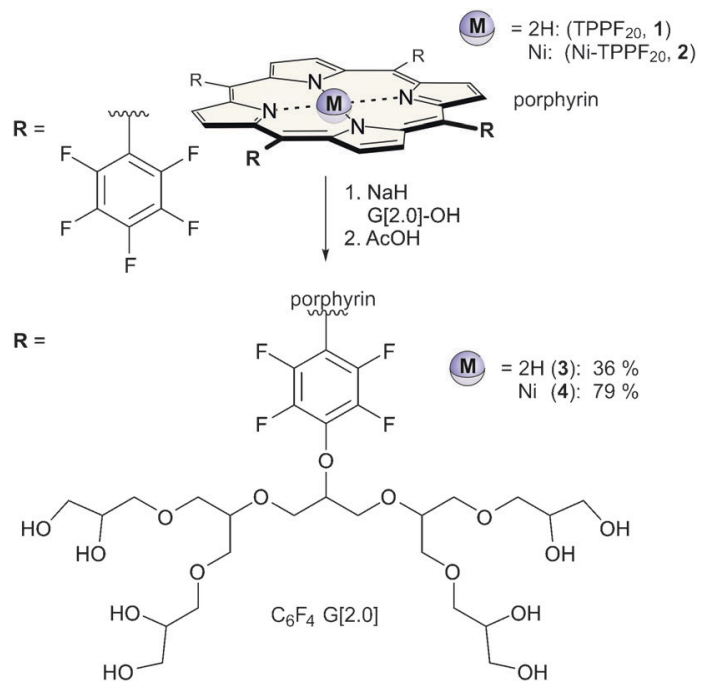

Fig. 2 Syntheses of the glycerol functionalised porphyrins 3 and 4 Experimental details are given in the ESI. $\dagger$

is shown in Fig. 2. Deprotection of the 32 alcohol functions was achieved quantitatively with acetic acid (Fig. 2).

In contrast to many other water-soluble porphyrins $s^{8,14,28,37}$ the glycerol functionalised derivatives $\mathbf{3}$ and $\mathbf{4}$ do not exhibit aggregation or excimer formation which is probably due to the large steric hindrance of the polyols. ${ }^{34,35}$ Solutions of 3 and 4 perfectly follow the Lambert-Beer law up to a concentration of $50 \mu \mathrm{m}$. NMR experiments do not show any changes in the line shape suggesting that there is no aggregation even at concentrations of $0.8 \mathrm{mM}$ (see ESI $\dagger$ ).

Compound 4 in water exhibits a Soret band at $409 \mathrm{~nm}$, which is indicative of a diamagnetic low-spin state. Addition of piperidine gives rise to a new band at $428 \mathrm{~nm}$ due to axial coordination and the associated spin state switch to the highspin triplet state (Fig. 3).

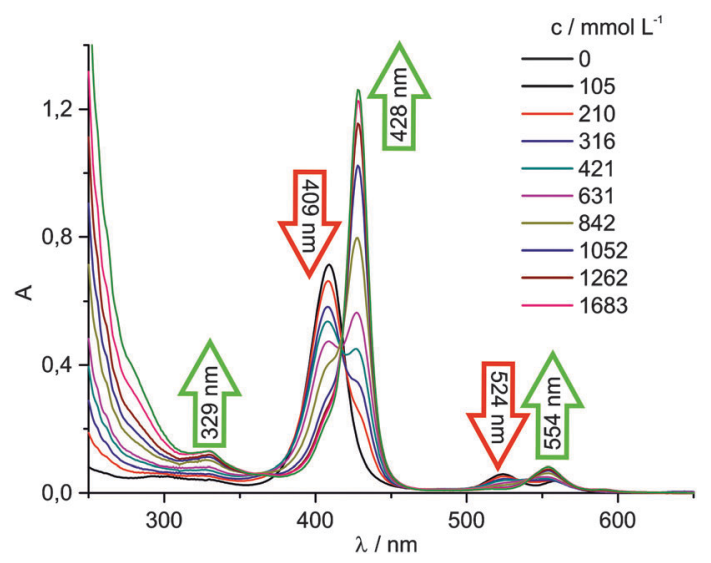

Fig. 3 UV-Vis spectra (top) of titration series of piperidine to Ni-porphyrin 4 $\left(4.05 \mu \mathrm{m}, 20^{\circ} \mathrm{C}\right)$ in water. Association constants for addition of one piperidine ligand $\left(K_{1}=0.48 \mathrm{~L} \mathrm{~mol}^{-1}\right)$, and the association of a second piperidine ligand $\left(K_{2}=14.7 \mathrm{~L} \mathrm{~mol}^{-1}\right)$ were determined from the UV-visible data (see ESI $\dagger$ ). The green arrows correspond to increasing absorption upon increasing piperidine concentration.

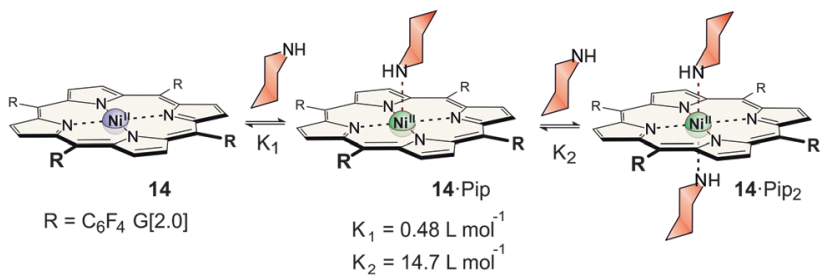

Fig. 4 Formation of the square pyramidal (4.Pip) and the square bipyramidal complexes (4.Pip 2 .

The titration experiment reveals very low values for the association constants $\left(K_{1}, K_{2}\right)$ (Fig. 4 , for details see the ESI $\dagger$ ) compared to the values for Ni-TPPF 20 (2) obtained in organic solution by similar experiments. $^{3-5}$ Water is an adverse solvent for axial coordination because it reduces the donor strength of ligands by hydrogen bonding. Nevertheless, the association constants obtained for piperidine are higher than those for many alkyl- and aryl-substituted Ni-porphyrins in organic solution. ${ }^{38-42}$ Except for very strong donor ligands, and very electron poor porphyrins, $K_{1}$ is known to be much smaller than $K_{2}{ }^{17,41,42}$ Spin change occurs upon binding of the first axial ligand which in turn activates the second axial binding site. Usually, the predominant species, therefore, is the $2: 1$, square bipyramidal complex. This is in agreement with our findings: $K_{2}$ is approximately 30 times larger than $K_{1}$ (see ESI $\dagger$ ).

Both magnetic species exhibit different ${ }^{1} \mathrm{H}$ NMR spectra, and their relative ratio can be quantified using ${ }^{1} \mathrm{H}$ NMR spectroscopy. Ligand exchange is fast on the NMR time scale, and an averaged shift of high-spin and low-spin species is observed at room temperature. Particularly, the chemical shift of the pyrrole protons is an excellent indicator of the ratio of high and low-spin Ni(II) in solution..$^{2-5}$ In pure complex 4 these protons resonate at $9.1 \mathrm{ppm}$, which is typical for a completely diamagnetic Ni-porphyrin. Upon addition of piperidine ( $\sim 1000$ eq.), the corresponding peak is shifted downfield to $52.7 \mathrm{ppm}$ which is the chemical shift of the pure triplet Ni-porphyrin. Hence, the molecule has almost completely switched to the high-spin state (Fig. 5).

Paramagnetic metal ions are known to decrease the proton relaxation time of the surrounding water molecules. ${ }^{43} \mathrm{Gd}^{3+}$ complexes (7 unpaired electrons), therefore, are widely used

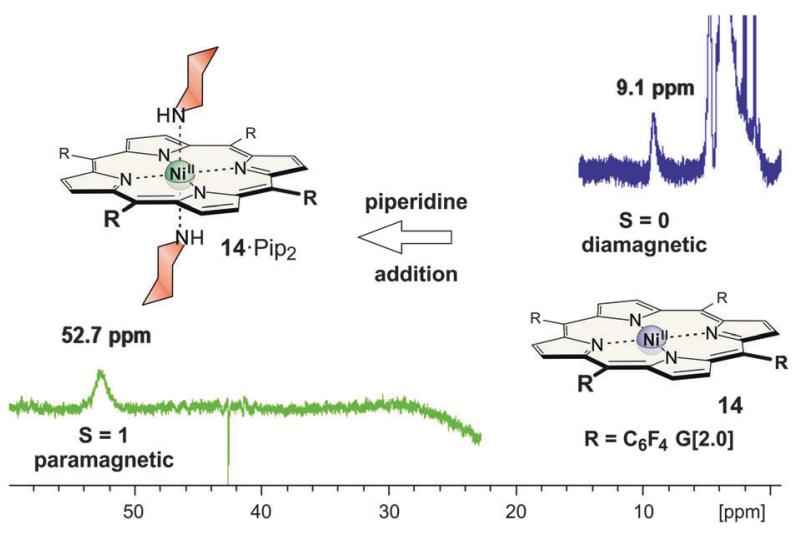

Fig. 5 NMR spectra $\left(\mathrm{D}_{2} \mathrm{O}, 500 \mathrm{MHz}, T=300 \mathrm{~K}\right)$ of Ni-porphyrin 4 $(0.8 \mathrm{mM})$ before (blue) and after (green) addition of piperidine. 


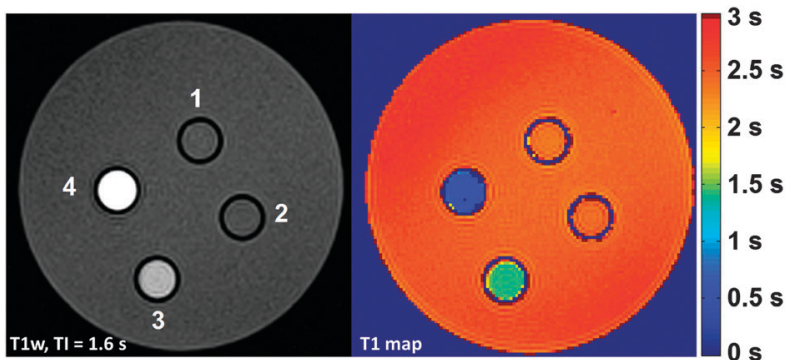

Fig. 6 MR images of 4 different solutions: 1. 4 (2 mM in water), 2. water, 3. water $+20 \%$ piperidine and 4.4 ( $2 \mathrm{mM}$ in water $+20 \%$ piperidine). For details see ESI. $\dagger$

as contrast agents in magnetic resonance imaging (MRI). ${ }^{44}$ Ni-porphyrin 4 in water is diamagnetic and inactive as a MRI contrast agent which is shown by $7 \mathrm{~T}$ MR images (note that nickel salts such as $\mathrm{NiCl}_{2} \cdot 6 \mathrm{H}_{2} \mathrm{O}$ are paramagnetic). Upon addition of piperidine as a strong axial ligand the complex changes to the paramagnetic state $(S=1)$ and the contrast is turned on (Fig. 6). In a $2 \mathrm{mM}$ solution in water the relaxation rate thereby rises from $0.71 \mathrm{~s}^{-1}$ (water $+20 \%$ piperidine) to $1.96 \mathrm{~s}^{-1}$ (factor $\sim 2.8$ ). The relaxivity (effectiveness in reducing the relaxation time of water protons, $\left.r_{1}\right)$ of the paramagnetic complex 4. $\mathrm{Pip}_{2}\left(0.63 \mathrm{mM}^{-1} \mathrm{~s}^{-1}\right)$ is slightly lower than $r_{1}$ of $\mathrm{Ni}^{2+}$ salts (aquo complex: $0.78 \mathrm{mM}^{-1} \mathrm{~s}^{-1}$ ) but is much higher than for other nickel complexes (e.g. EDTA complex: $0.11 \mathrm{mM}^{-1} \mathrm{~s}^{-1}$ ). The MR images demonstrate that porphyrins such as 4 could be viewed as a first step towards the development of responsive contrast agents. $^{45,46}$

A neutral, water-soluble, oligoglycerol dendron substituted Ni-porphyrin was synthesised whose spin state was switched from completely diamagnetic (low-spin) to paramagnetic (high-spin) by addition of piperidine. Both, the Ni-porphyrin and the free base are easily accessible in a two-step procedure from commercially available starting materials. No aggregation or excimer formation was observed even at high concentrations in water. The hydrophilic Ni-porphyrin complex is an excellent candidate for spin switching in water. The longitudinal relaxivity $r_{1}$ of the paramagnetic state which is unusually high for an $S=1$ complex $\left(0.63 \mathrm{mM}^{-1} \mathrm{~s}^{-1}\right)$ and the spin switching mechanism could provide a basis for responsive contrast agents for MRI. The metal-free porphyrin should be suitable for applications such as photooxidation or photodynamic therapy in physiological environments.

\section{Notes and references}

1 S. Venkataramani, U. Jana, M. Dommaschk, F. D. Sönnichsen, F. Tuczek and R. Herges, Science, 2011, 331, 445-448.

2 R. Herges, Nachr. Chem., 2011, 59, 817-821.

3 S. Thies, H. Sell, C. Schütt, C. Bornholdt, C. Näther, F. Tuczek and R. Herges, J. Am. Chem. Soc., 2011, 133, 16243-16250.

4 S. Thies, H. Sell, C. Bornholdt, C. Schütt, F. Köhler, F. Tuczek and R. Herges, Chem. - Eur. J., 2012, 18, 16358-16368.

5 S. Thies, C. Bornholdt, F. Köhler, F. D. Sönnichsen, C. Näther, F. Tuczek and R. Herges, Chem. - Eur. J., 2010, 16, 10074-10083.

6 F. Matino, G. Schull, U. Jana, F. Köhler, R. Berndt and R. Herges, Chem. Commun., 2010, 46, 6780-6782.
7 E. B. Fleischer, J. M. Palmer, T. S. Srivastava and A. Chatterjee, J. Am. Chem. Soc., 1971, 93, 3162-3167.

8 R. F. Pasternack, P. R. Huber, P. Boyd, G. Engasser, L. Francesconi, E. Gibbs, P. Fasella, G. Cerio Venturo and L. d. Hinds, J. Am. Chem. Soc., 1972, 94, 4511-4517.

9 J. Turay, P. Hambright and N. Datta-Gupta, J. Inorg. Nucl. Chem., 1978, 40, 1687-1688.

10 F. R. Longo, M. G. Finarelli and J. B. Kim, J. Heterocycl. Chem., 1969, 6, 927-931.

11 N. Datta-Gupta and T. J. Bardos, J. Heterocycl. Chem., 1966, 3, 495-502.

12 T. Fujimoto, H. Umekawa and N. Nishino, Chem. Lett., 1992, 37-40.

13 M. Krishnamurthy, Indian J. Chem., 1977, 15B, 964.

14 K. Kano, M. Takei and S. Hashimoto, J. Phys. Chem., 1990, 94, 2181-2187.

15 P. Hambright and E. B. Fleischer, Inorg. Chem., 1970, 9, 1757-1761.

16 R. Fiel, J. Howard, E. Mark and N. Gupta, Nucleic Acids Res., 1979, 6, 3093-3118.

17 T. La, R. A. Richards, R. S. Lu, R. Bau and G. M. Miskelly, Inorg. Chem., 1995, 34, 5632-5640.

18 T. La, R. Richards and G. M. Miskelly, Inorg. Chem., 1994, 33, 3159-3163.

19 M. Ravikant, D. Reddy and T. K. Chandrashekar, J. Chem. Soc., Dalton Trans., 1991, 2103-2108.

20 K. Bütje and K. Nakamoto, Inorg. Chim. Acta, 1990, 167, 97-108.

21 M. Ethirajan, Y. Chen, P. Joshi and R. K. Pandey, Chem. Soc. Rev., $2011,40,340-362$.

22 R. Bonnett, Chem. Soc. Rev., 1995, 24, 19-33.

23 P. Mineo, E. Scamporrino and D. Vitalini, Macromol. Rapid Commun., 2002, 23, 681-687.

24 V. Villari, P. Mineo, E. Scamporrino and N. Micali, Chem. Phys., 2012, 409, 23-31.

25 J. a. P. Tomé, M. G. Neves, A. C. Tomé, J. A. Cavaleiro, A. F. Mendonça, I. N. Pegado, R. Duarte and M. L. Valdeira, Bioorg. Med. Chem., 2005, 13, 3878-3888.

26 A. G. Griesbeck, M. A. Miranda and J. Uhlig, Photochem. Photobiol. Sci., 2011, 10, 1431-1435.

27 D. Samaroo, M. Vinodu, X. Chen and C. M. Drain, J. Comb. Chem., 2007, 9, 998-1011.

28 D. Oulmi, P. Maillard, C. Vever-Bizet, M. Momenteau and D. Brault, Photochem. Photobiol., 1998, 67, 511-518.

29 J. E. Bradshaw, K. A. Gillogly, L. J. Wilson, K. Kumar, X. Wan, M. F. Tweedle, G. Hernandez and R. G. Bryant, Inorg. Chim. Acta, 1998, 275-276, 106-116.

30 A. G. Griesbeck, M. Schäfer and J. Uhlig, Adv. Synth. Catal., 2008, 350, 2104-2108.

31 C. Kordel, C. S. Popeney and R. Haag, Chem. Commun., 2011, 47, 6584-6586.

32 M. Wyszogrodzka and R. Haag, Chem. - Eur. J., 2008, 14, 9202-9214.

33 M. Wyszogrodzka, K. Möws, S. Kamlage, J. Wodzinska, B. Plietker and R. Haag, Eur. J. Org. Chem., 2008, 53-63.

34 T. Heek, C. Fasting, C. Rest, X. Zhang, F. Würthner and R. Haag, Chem. Commun., 2010, 46, 1884-1886.

35 T. Heek, F. Würthner and R. Haag, Chem. - Eur. J., 2013, 19, 10911-10921.

36 G. R. Geier III and J. S. Lindsey, Tetrahedron, 2004, 60, 11435-11444.

37 R. R. Das, R. F. Pasternack and R. A. Plane, J. Am. Chem. Soc., 1970, 92, 3312-3316.

38 B. D. McLees and W. S. Caughey, Biochemistry, 1968, 7, 642-652.

39 S. J. Cole, G. C. Curthoys, E. A. Magnusson and J. N. Phillips, Inorg. Chem., 1972, 11, 1024-1028.

40 F. A. Walker, E. Hui and J. M. Walker, J. Am. Chem. Soc., 1975, 97, 2390-2397.

41 D. Kim, Y. O. Su and T. G. Spiro, Inorg. Chem., 1986, 25, 3988-3993.

42 Y. Song, R. E. Haddad, S.-L. Jia, S. Hok, M. M. Olmstead, D. J. Nurco, N. E. Schore, J. Zhang, J.-G. Ma, K. M. Smith, S. Gazeau, J. Pécaut, J.-C. Marchon, C. J. Medforth and J. A. Shelnutt, J. Am. Chem. Soc., 2005, 127, 1179-1192.

43 R. B. Lauffer, Chem. Rev., 1987, 87, 901-927.

44 H. Gries, Top. Curr. Chem., 2002, 221, 1-24.

45 G. Angelowski and I. Mamedov, Curr. Inorg. Chem., 2011, 1, 76-90.

46 C. Tu, E. A. Osborne and A. Y. Louie, Ann. Biomed. Eng., 2011, 39, 1335-1348. 